\title{
Assessment of Self-Perceived End-of-Life Care Competencies of Intensive Care Unit Providers
}

\author{
Marcos Montagnini, M.D., FACP, ${ }^{1,2}$ Heather Smith, Ph.D.,, ${ }^{3,4}$ and Toni Balistrieri, R.N., M.S.N., CLCP 5
}

\begin{abstract}
Background: The need for improved (end-of-life) EOL care in the intensive care unit (ICU) has gained attention in the medical literature over the last 10 years. The purpose of this study is to describe ICU health care providers' self-perceived knowledge, attitudes, and behaviors related to the provision of EOL care as a first step in planning educational interventions for ICU staff.

Methods and results: One hundred eighty-five ICU staff members of an academic affiliated tertiary medical center in Milwaukee, Wisconsin received the survey, the Scale of End-of-Life Care in the ICU (EOLC-ICU), a new questionnaire developed for this study. The response rate was $50.3 \%$.

Conclusion: We found that having previous EOL care education was common among ICU staff. However, several deficiencies in self-perceived EOL competencies were identified among staff, particularly in the areas of communication, continuity of care, and decision-making process. Nursing and medical staff also had different perceptions on how certain EOL behaviors were carried out in the ICU. Educational interventions will be implemented in our ICU in an effort to improve staff preparedness for the provision of quality EOL care.
\end{abstract}

\section{Introduction}

D EATH IS COMMON in the intensive care unit (ICU) setting. There are 540,000 deaths per year in ICUs, which corresponds to approximately $20 \%$ of all deaths in the United States. ${ }^{1}$ Approximately half of the patients who die in the hospital are cared for in an ICU within 3 days of death. ${ }^{2}$ Despite the high prevalence of deaths in the ICU, the provision of end-of-life (EOL) care in this setting remains deficient. Patients dying in ICUs continue to suffer pain and other distressing symptoms and receive aggressive therapies until the moment of death. ${ }^{3-7}$ Patient satisfaction with pain control is worse in ICUs than other hospital settings. ${ }^{3,6}$ Families and surrogates of patients treated in ICUs report that the quality of communication with critical care and other hospital clinicians is often poor. ${ }^{5,7}$ Conflicts between clinicians and family members are also common in ICUs. ${ }^{8-9}$

The need for improved EOL care in the ICU has gained attention in the medical literature over the last 10 years. The End-of-Life Care in the ICU Working Group was established in 1998 to develop a national agenda for research, education, and clinical efforts to improve care of patients dying in ICUs. ${ }^{10}$ The ethics committee of the Society of Critical Care
Medicine published written recommendations for EOL care in the ICU from the perspective of coexisting palliative care and intensive care. ${ }^{11}$ The committee stated that "intensive care clinicians must become as skilled and knowledgeable at forgoing life-sustaining treatment as they are at delivering care aimed at survival and cure." ${ }^{11}$ In 2003, Clarke and colleagues addressed deficiencies in EOL care in ICUs by using a consensus process to identify key domains of care and associated quality performance indicators. ${ }^{12}$

More recently, the American Academy of Critical Care Medicine published a consensus document with recommendations for improvement of EOL care in the ICU. ${ }^{13}$ Familycentered care, communication, ethical aspects related to withdrawal of life-sustaining therapies, symptom management, and care at the time of and after death were all recognized as comprehensive ideals for managing EOL care in the ICU. ${ }^{13}$ In addition, the document established a comprehensive agenda for improving EOL care in the ICU to guide research, quality improvement efforts, and educational curricula. $^{13}$

As the field of palliative care moves forward, more research is needed on the impact of educational interventions on the quality of EOL care in the ICU, as lack of knowledge among

\footnotetext{
${ }^{1}$ Division of Geriatric Medicine, Department of Internal Medicine, University of Michigan, Ann Arbor, Michigan.

${ }^{2}$ Geriatrics Research and Education Clinical Center (GRECC), VA Ann Arbor Healthcare System, Ann Arbor, Michigan.

${ }^{3}$ Department of Psychiatry, Medical College of Wisconsin, Milwaukee, Wisconsin.

${ }^{4}$ Clement J. Zablocki Veterans Affairs Medical Center, Milwaukee, Wisconsin.

${ }^{5}$ Columbia St. Mary's Hospital, Milwaukee, Wisconsin.

Accepted August 24, 2011.
} 
ICU providers may significantly limit the quality of care of dying patients in this setting.

The purpose of this study is to describe ICU health care providers' self-perceived knowledge, attitudes, and behaviors related to the provision of EOL care as a first step in planning educational interventions for ICU staff. Examination of the psychometric properties of the Scale of End-of-Life Care in the ICU (EOLC-ICU), a new questionnaire developed for this study, also was conducted.

\section{Methods}

The study took place on the ICU at the Clement J. Zablocki Veterans Administration Medical Center (ZVAMC), which is an academic affiliated tertiary medical center in Milwaukee, Wisconsin. The medical care in the ICU is provided primarily by medicine and surgical teams comprising attending physicians, house officers, and medical students with consultations from a pulmonary/critical care team to assist with the management of more severely ill patients and patients on mechanical ventilation. The pulmonary critical care team comprises an attending physician certified in pulmonary critical care, pulmonary critical care fellows, medicine residents, and medical students. Every year, approximately 200 patients are admitted to the ICU, and $23 \%$ to $27 \%$ of medical center deaths occur in the ICU.

All health care providers in the ICU, including nursing, medicine (attending physicians, fellows, residents, and medical students), respiratory therapy, physical therapy, chaplains, social workers, dietitians, and medical instrument technicians were eligible to participate in the study. Participation was voluntary, and subjects who did not want to participate in the study were excluded.

Participants were asked to complete the EOLC-ICU, a survey developed to assess self-perceived competencies pertinent to provision of EOL care in the ICU (Appendix 1). The survey contained demographic questions including role in the ICU, specialty, number of years in practice, previous EOL education (yes or no), type of education (lectures, self-study, course, palliative care certification, and other), and 28 questions addressing self-perceived knowledge, attitudes, and behaviors pertinent to seven EOL care domains. The domains, which were proposed by Clarke and colleagues $^{12}$ for improved EOL in the ICU, included patient and family decision making, communication within the team and with patients and families, continuity of care, emotional and practical support for patients and families, symptom management and comfort care, spiritual support for patients and families, and emotional and organizational support for ICU clinicians. Table 1 identifies the specific items on each subscale.

EOLC-ICU items were developed by interdisciplinary palliative care and ICU experts, including representatives from medicine, psychology, and nursing. Feedback from palliative medicine providers and individuals with expertise in test construction not associated with the facility or the study was incorporated to arrive at the final 28-item version of the scale. As described in Table 1, the number of EOLC-ICU items per EOL domain varied, which was intentional in an effort to design the scale in a manner that reflects the relative areas of emphasis within an ICU setting. Items were also more heavily weighted toward knowledge and behaviors than attitudes, as it was hoped that the EOLC-ICU might be utilized
Table 1. Scale of End-of-Life Care in the ICU (EOLC-ICU) Items and Subscale Internal CONSISTENCY Reliability

\begin{tabular}{lrcc}
\hline Scale & $\begin{array}{c}\text { \# of } \\
\text { items }\end{array}$ & $\begin{array}{c}\text { Items } \\
\text { (Appendix 1) }\end{array}$ & $\begin{array}{c}\text { Cronbach's } \\
\alpha\end{array}$ \\
\hline Total & 28 & $1-28$ & 0.92 \\
Knowledge & 12 & $1-12$ & 0.92 \\
Attitudes & 5 & $13-17$ & 0.72 \\
Behaviors & 11 & $18-28$ & 0.90 \\
Decision making & 6 & $6,7,13,14,18,19$ & 0.90 \\
Communication & 7 & $16,20,21,22,23,24,25$ & 0.88 \\
Continuity of care & 2 & 26,27 & 0.66 \\
emotional support for & 3 & $9,10,11$ & 0.84 \\
$\quad$ patients and families & & & \\
Symptom management & 7 & $1,2,3,4,5,8,15$ & 0.91 \\
Spiritual support & 1 & 12 & $\mathrm{~N} / \mathrm{A}$ \\
Emotional support for & 2 & 17,28 & 0.25 \\
$\quad$ staff & & & \\
\hline
\end{tabular}

as a tool for measuring the effectiveness of future EOL care educational interventions for ICU staff. The EOLC-ICU questions were scored on a 5-point Likert scale, as follows: "strongly disagree" (1), "disagree" (2), "neutral" (3), "agree" (4), and "strongly agree" (5). Items checked as "not applicable" by respondents were coded as zero. Total EOLC-ICU scores were calculated by summing the responses for all 28 items, with a possible range from 0 to 140 with higher scores indicating greater perceived competency regarding EOL care in the ICU setting. Scores for the seven EOL domain subscales and the knowledge, attitudes, and behaviors subscales also were calculated by adding participants' responses to the relevant items on each subscale.

\section{Statistical analysis}

Data analysis was descriptive and correlational in nature. Means were calculated for each item in order to identify the areas of greatest perceived competency. Potential differences in self-perceived EOL care competencies among groups were calculated using analysis of variance (ANOVA) procedures. Comparisons of the mean scores of those who had previous EOL education and those who did not were conducted via $t$ tests. Correlations were calculated to examine the relationship between the number of years in practice and self-perceived EOL care competencies, years in practice and total types of education, and having previous EOL education and selfperceived EOL care competencies. In addition, internal consistency reliability of the survey and its subscales was assessed.

\section{Results}

One hundred eighty-five ICU staff members received the survey. The response rate was $50.3 \%$ ( $n=93$ surveys). The majority of responses were from nurses $(40.9 \%)$ and physicians $(26.9 \%)$ (Table 2$)$. The specialties most common among physicians were internal medicine (IM) (52\%), pulmonary/ critical care (ICU) (28\%), and general surgery (20\%). Participants' years in practice ranged from 0 to 38 years with a mean of 14.91 years. Almost 70\% (69.9\%) of respondents reported having previous EOL care education through lectures, selfstudy, course work, palliative care certification, and other 
Table 2. Demographic Characteristics of Study Participants $(N=91)$

\begin{tabular}{lc}
\hline Role in the ICU & $\mathrm{N}(\%)$ \\
\hline Nursing & $38(40.9)$ \\
Attending physician & $25(26.9)$ \\
Internal medicine & $13(14.2)$ \\
General surgery & $5(5.37)$ \\
Critical care & $7(7.5)$ \\
Anesthesia & $1(1)$ \\
Cardiothoracic surgery & $1(1)$ \\
Other & $7(7.5)$ \\
PGY-4 & $5(5.4)$ \\
Fellow & $3(3.2)$ \\
Medical student & $6(6.5)$ \\
Chaplain & $4(4.3)$ \\
Social work & $3(3.2)$ \\
Respiratory therapy & $2(2.2)$ \\
Dietary & $1(1.1)$ \\
Other & $4(4.3)$ \\
\hline
\end{tabular}

types of education (range: 0 to 3 types of education). The participants reported having had one type of education $(41.9 \%)$ more frequently than two $(n=14.9 \%)$ or three types $(6.5 \%)$.

Table 1 provides information regarding the internal consistency reliability of the total EOLC-ICU scale and its subscales. Results indicated that the internal consistency reliability of the total survey was high and ranged from generally adequate for the attitudes and continuity of care subscales to high for the remaining subscales. The one exception was poor internal consistency reliability for the subscale measuring emotional support for staff; it is possible that the small number of items (two) contributing to this domain truncated the results. It was not possible to compute an internal consistency reliability coefficient for the subscale assessing spiritual support for patients and families due to it being limited to one item.

The mean ratings of self-perceived competency for each domain are outlined in Table 3 . The greatest self-perceived competence was in patient and family support and the least self-perceived competence was in continuity of care.

Correlation analysis demonstrated that years in practice was significantly correlated with self-perceived competency in providing emotional support to patients and families $(r=0.25, p=0.05)$. Years in practice was also significantly correlated with total types of education $(r=0.27, p=0.05)$. Years in practice was not significantly correlated with per-

\section{Table 3. Self-Perceived Competency Ratings $($ MEAN \pm SD) FOR EOL CARE DOMAINS AMONG STUdy PARTICIPANTS $(N=91)$}

\begin{tabular}{lc} 
EOL care domain & Self-rating \\
\hline Patient and family support & $3.99 \pm 0.92$ \\
Spiritual support & $3.93 \pm 1.15$ \\
Symptom management & $3.79 \pm 1.19$ \\
Decision-making capacity & $3.75 \pm 1.17$ \\
Communication & $3.36 \pm .0 .99$ \\
Staff support & $3.03 \pm 0.97$ \\
Continuity of care & $2.67 \pm 1.17$ \\
\hline
\end{tabular}

ceived EOL knowledge $(r=0.13)$, attitudes toward EOL care in the ICU $(r=0.08)$, EOL care behaviors $(r=0.08)$, total score on the survey $(r=0.09)$, or any of the seven EOL care domains. Having previous EOL education was significantly correlated with the following: self-perceived EOL knowledge (Spearman's rho $=0.32, p=0.01$ ), self-perceived competency in decision making $(\mathrm{rho}=0.23, p=0.05)$, providing emotional support to patients and families (rho $=0.24, p=0.05)$, symptom management $(\mathrm{rho}=0.30, p=0.01)$, and the total score (rho $=0.23, p=0.05$ ).

The mean differences of self-perceived competencies between medical (attendings, fellows, and students) and nursing staff were calculated using the $t$ test (Table 4). Comparisons among other disciplines (e.g., social work, dietary) were not calculated due to small sample sizes, which would not allow for sufficient power to detect significant differences. The mean difference between medical and nursing staff in self-perceived behaviors was statistically significant $(t=3.846, p<0.0001)$ with medical staff reporting more frequent EOL care behaviors occurring in the ICU than nursing staff. The behaviors subscale was further broken down into individual behaviors and team behaviors based on a content analysis of the behavior-related items on the scale. This resulted in two behavior subscales containing the following items: individual behaviors (items 18 and 19) and team behaviors (items 20 through 28). A significant difference was found between the groups for team behaviors $(t=4.40$, $p<0.0001)$, with medical providers reporting greater frequency of team-related behaviors than did nursing. In addition, the mean difference in perceived communication was statistically significant $(t=6.179, \mathrm{p}<0.0001)$. Again, medical staff rated communication regarding EOL care in the ICU as more positive than did nursing.

Medical specialty comparisons (surgery [group1], [IM] [group 2], and ICU [group 3]) using one-way ANOVA indicated significant differences among groups in the following areas: knowledge $(F=4.596, d f=2,22, p=0.021)$, decision making $(F=3.295, d f=2,23, p=0.055)$, spiritual support $(F=3.730, d f=2,22, p=0.040)$, and total score $(F=4.596$, $d f=2,22, p=0.020$ ). Subsequent post hoc analysis indicated that significant differences were accounted for by the following: knowledge (group 1 [mean $=3.46]$ versus group 2 $[$ mean $=4.27]$ ), decision making (group 1 [mean $=3.50]$ versus

Table 4. Mean Self-Perceived EOl Care Competencies for Medical and Nursing Staff

\begin{tabular}{lcc}
\hline Perceived competencies & Medical staff & Nursing staff \\
\hline Knowledge & 4.11 & 4.26 \\
Attitudes & 4.24 & 4.19 \\
Behaviors* & 3.56 & 2.87 \\
Individual behaviors & 3.74 & 3.76 \\
Team behaviors* & 3.53 & 2.69 \\
Decision making & 4.23 & 4.03 \\
Communication* & 4.04 & 2.92 \\
Continuity of care & 2.71 & 2.84 \\
Patient/family support & 3.97 & 4.23 \\
Symptom management & 4.11 & 4.37 \\
Spiritual support & 3.79 & 4.10 \\
Staff support & 3.06 & 3.03 \\
\hline
\end{tabular}

${ }^{*} p<0.0001$; all other mean differences were nonsignificant with $p>0.05$. 
group 2 [mean $=4.47]$ ), spiritual support (group 1 [mean = $2.67]$ versus group $2[$ mean $=4.0]$ ), and total score (group 1 $[$ mean $=3.44]$ versus group 2 [mean $=4.04]$, group 1 [mean $=$ $3.44]$ versus group 3 [mean $=4.19])$. In other words, surgeons reported less knowledge about EOL care in the ICU setting, less confidence regarding EOL decision making, and less confidence in their ability to address the spiritual needs of patients and families relative to IM physicians. In addition, on average surgeons achieved significantly lower total scores on the EOLC-ICU relative to IM and ICU physicians.

Participants also provided comments related to EOL care in the ICU (Table 5). Analysis of the thematic content of the comments indicates that this qualitative data paralleled the quantitative results. Namely, comments reflected concerns about communication among staff and among clinicians, patients, and families at EOL, a potential knowledge deficit resulting in underutilization of symptom management strategies at EOL, and a desire for additional education regarding EOL care in the ICU.

\section{Discussion}

Our study expands on the existing literature on perceived EOL care competencies among ICU providers. It also confirms prior findings in the literature that EOL care education is needed in the ICU and identifies areas of greater need for education.

Several studies have addressed the need for improved EOL care education for ICU clinicians as lack of formal EOL care education is one of the top barriers to quality EOL care in this setting. ${ }^{14-23}$ Studies also have demonstrated that educating critical care clinicians in specific aspects of communication with families, including listening to families and running supportive conferences, improves families' satisfaction with EOL care. ${ }^{24-26}$

We found that palliative care education was common among participants. Almost $70 \%$ of participants had some type of EOL care education through lectures, self-study, course work, palliative care certification, and other types of education. Further correlation analysis demonstrated that the number of years in practice was significantly associated with frequency of EOL education. These findings contrast with a study involving 626 physicians and nurses that addressed barriers to quality EOL care in ICUs. ${ }^{18}$ That study demonstrated that EOL care education was uncommon among the majority of participants, who reported an average of less than 1 week of education in palliative care despite being in practice for at least 15 years. ${ }^{18}$ The high frequency of EOL care education found in our study most likely represents the culture of the ZVAMC, which values EOL care. Over the last few years, the ICU staff has been exposed to several educational initiatives developed by the palliative care program at the ZVAMC in collaboration with the Medical College of Wisconsin. These include palliative care grand rounds, palliative care experiences for trainees, a faculty development course in palliative care, and an interprofessional fellowship program in palliative care. ${ }^{27}$ Even though the type of EOL education may have varied among the participants, EOL care education was associated with a greater self-perception of having EOL care knowledge and higher competency levels in providing more effective symptom management, emotional support to patients and families, and participation in decision-making processes.

Participants reported the highest levels of self-perceived competencies in providing emotional support to patients and families, spiritual support, symptom management, and decision making regarding EOL. Participants' least perceived competencies were in communication, staff support, and continuity of care. These findings suggest that, when planning for educational interventions, the ICU staff will most likely have unique learning needs when compared with staff from different areas. For instance, a study on EOL care competencies among 695 oncology nurses documented higher competency levels in communication, pain control, and comfort care interventions. $^{15}$

Our study demonstrated differences in perceived EOL care behaviors carried out by the disciplines in the ICU. When the

Table 5. Comments by Disciplines

\begin{tabular}{|c|c|}
\hline Discipline & Comment \\
\hline $\begin{array}{l}\text { Attending } \\
\text { physicians }\end{array}$ & $\begin{array}{l}\text { "Palliative Care Consultation Team should be consulted more often and sooner (especially when family has a hard } \\
\text { time accepting that the loved one is dying)." } \\
\text { "Need to make this core curriculum with medical students, spending one month in a hospice setting." }\end{array}$ \\
\hline Resident & $\begin{array}{l}\text { "I've always felt that more end-of-life support is needed in ICU for critically ill patients, but also for chronically ill } \\
\text { patients and Heme/Onc patients to better plan for the best end-of-life quality of life." }\end{array}$ \\
\hline Fellow & "Good luck improving the VA end-of-life care-it is a very worthwhile and important task." \\
\hline Nursing staff & $\begin{array}{l}\text { "We tend to have conflicts with new MDs with code status being changed. We have conflicting messages given to } \\
\text { family members, which leads to confusion, distress, distrust, and families unable to make final decisions." } \\
\text { "I think that the MDs need to address code status and end-of-life care earlier. Sometimes the need to cure overrides } \\
\text { the need for clear vision re the patient's true status and wishes." } \\
\text { "There is a wide difference in each team for end-of-life care-sometimes what is decided with one team may change } \\
\text { with the next team, confusing the families. Very hard on nursing staff. Also, patient may make a decision and } \\
\text { when they code or get to end of life, the family changes the decision." } \\
\text { "Physicians drop the ball on a regular basis." } \\
\text { "End-of-life care, withdrawal of support, etc., are less distressing than the providing of futile cares that prolong the } \\
\text { dying process, from my nursing viewpoint." } \\
\text { "Conflicting caregivers sometimes make the decisions of families more difficult." } \\
\text { "Dying patients are very under-medicated as physicians are afraid of patient becoming dependent, or the book says } \\
\text { you can only have small amount of a drug, while the patient is moaning and dying in misery. I would not want to } \\
\text { be here for end of life." }\end{array}$ \\
\hline
\end{tabular}


behavior subscale was broken down into individual and team behaviors, a significant difference was found between the nursing and medical staff. Nursing staff were significantly less likely than medical staff to perceive that team behaviors were carried out adequately in the ICU. Also, nursing staff were significantly less likely than medical staff to view communication regarding EOL care as being adequate. These findings support the previously documented differences between nurses' and physicians' perceptions of EOL care practices, particularly related to communication. ${ }^{18}$ A study addressing physicians' and nurses' perceptions of barriers to quality EOL care in ICUs documented that physicians had greater confidence in communication-based skills than did nurses, whereas nurses reported higher confidence in certain areas of symptom management (e.g., managing opioids). ${ }^{18}$ Interestingly, $51 \%$ of nurses in that study indicated that they were less prepared than physicians to discuss EOL care with patients/families. ${ }^{18}$

Another interesting finding in our study was that nurses' comments (Table 5) clearly indicated the existence of conflicts between nurses and physicians and within teams, in addition to perceived lack of physician preparedness to address EOL care. Conflicts between nurses and physicians are common in ICUs. ${ }^{8,28-31}$ In a large study on the prevalence of conflicts among 5268 ICU clinicians, Azoulay and colleagues ${ }^{28}$ demonstrated that nurse-physician conflicts were the most common, were rated as severe, and created job strains. Frick and coworkers $^{29}$ demonstrated that for two-thirds of ICU patients dying in the hospital, the physician and the nurse disagreed about treatment goals. Studdert et al. ${ }^{30}$ documented that conflicts were not only common in the care of patients with prolonged stays in the ICU but also that one-third of them occurred within the ICU team. Breen and colleagues ${ }^{8}$ documented that conflicts among ICU staff occurred in $48 \%$ of the cases and were related to decisions about life-sustaining treatments, communication, and pain control. Beckstrand and coworkers's ${ }^{31}$ study on critical care nurses' perceived barriers and supportive behaviors to providing EOL care to patients demonstrated that the biggest obstacles were physicians' disagreements about the plan of care and physicians' avoidance of conversations with patients' families. These findings emphasize the need for education in teamwork and conflict resolution for ICU providers in order to optimize the quality of EOL care delivered in this setting.

The analysis of physicians' perceptions regarding knowledge related to EOL care in the ICU demonstrated that surgeons were less likely to endorse having adequate EOL knowledge than IM physicians. In addition, surgeons perceived spiritual care in the ICU to be lacking relative to the perception of IM physicians. This finding supports the need for expanding EOL care education to surgeons.

Our study has several limitations. First, it was done at a VA academic affiliated medical center, which limits the generalization of our findings to other settings. Second, the study involved a new, not yet validated instrument. However, the EOLC-ICU does appear to have promise as a useful research tool, as internal consistency for the total scale and its subscales was high. Third, despite a moderately high response rate $(50.3 \%)$ by participants, it is likely that those who responded were more interested in EOL care. If so, our study may overestimate the perceived EOL competencies among ICU providers. Finally, given the self-report nature of the data, the study assesses clinicians' self-perceived rather than actual competence in providing EOL care in the ICU setting.

\section{Conclusion}

We found that having previous EOL care education was common among ICU staff. However, several deficiencies in self-perceived EOL competencies were identified among staff, particularly in the areas of communication, continuity of care, and decision-making process. Nursing and medical staff also had different perceptions on how certain EOL behaviors were carried out in the ICU. Educational interventions will be implemented in our ICU in an effort to improve staff preparedness for the provision of quality EOL care.

\section{Author Disclosure Statement}

No competing financial interests exist.

\section{References}

1. Angus DC, Barnato AE, Linde-Zwirble WT, Weissfeld LA, Watson RS, Rickert T, Rubenfeld GD; on behalf of the Robert Wood Johnson Foundation ICU End-of-Life Peer Group: Use of intensive care at the end of life in the United States: An epidemiologic study. Crit Care Med 2004;32:638-643.

2. The SUPPORT Principal Investigators: A controlled trial to improve care for seriously ill hospitalized patients: The study to understand prognoses and preferences for outcomes and risks of treatments (SUPPORT). JAMA 1995;274, 1591-1598.

3. Desbiens NA, Wu AW, Broste SK, Wenger NS, Connors AF, Lynn J, Yasui Y, Phillips RS, Fulkerson W: Pain and satisfaction with pain control in seriously ill hospitalized adults: Findings from the SUPPORT research investigators. Crit Care Med 1996;24:1953-1961.

4. Lynn J, Teno JM, Phillips RS, Wu AW, Desbiens N, Harrold J, Claessens MT, Wenger N, Kreling B, Connors AF: Perceptions by family members of the dying experiences of older and seriously ill patients. Ann Intern Med 1997;126: 97-106.

5. Nelson JE, Meier DE, Oei EJ, Nierman DM, Senzel RS, Manfredi PL, Davis SM, Morrison SM: Self-reported symptom experience of critically ill cancer patients receiving intensive care. Crit Care Med 2001;29:277-282.

6. Somogyi-Zalud E, Zhong Z, Lynn J, Dawson NV, Hamel MB, Desbiens NA: Dying with acute respiratory failure or multiple organ system failure with sepsis. I Am Geriatr Soc 2000;48:S140-S145.

7. Malacrida R, Bettelini CM, Degrate A, Martinez M, Badia F, Piazza J, Vizzardi N, Wullschleger R, Rapin CH: Reasons for dissatisfaction: A survey of relatives of intensive care patients who died. Crit Care Med 1998;26:1187-1193.

8. Breen CM, Abernethy AP, Abbott KH, Tulsky JA: Conflict associated with decisions to limit life-sustaining treatment in intensive care units. J Gen Inter Med 2001;16:283-289.

9. Abbott KH, Sago JG, Breen CM, Abernethy AP: Families looking back: One year after discussion of withdrawal or withholding of life-sustaining support. Crit Care Med 2001; 29:197-201.

10. Rubenfeld GD, Curtis JR: End-of-life care in the intensive care unit: A research agenda. Crit Care Med 2001;29:20012006.

11. Troug RD, Cist AFM, Brackett SE, Burns JP, Curley MAQ, Danis M, DeVita MA, Rosenbaum SH, Rothenberg DM, 
Sprung CL, Webb SA, Wlody GS, Hurford WE: Recommendations for end-of-life care in the intensive care unit: The Ethics Committee of the Society of Critical Care Medicine. Crit Care Med 2001;29:2332-2348.

12. Clarke EB, Curtis JR, Luce JM, Levy M, Danis M, Nelson J, Solomon MZ: Quality indicators for end-of-life care in the intensive care unit. Crit Care Med 2003;31:2255-2262.

13. Truog RD, Campbell ML, Curtis JR, Haas CE, Luce JM, Rubenfeld GD, Rushton CH, Kaufman DC: Recommendations for end-of-life care in the intensive care unit: A consensus statement by the American Academy of Critical Care Medicine. Crit Care Med 2008;36:953-963.

14. Levy MM: End-of-life care in the intensive care unit: Can we do better? Crit Care Med 2001;29:N56-N61.

15. White KR, Coyne PJ, Patel UB: Are nurses adequately prepared for end-of-life care? J Nurs Scholarsh 2001;33:147-151.

16. Cook D, Rocker G, Heyland D: Dying in the ICU: Strategies that may improve end-of-life care. Can J Anesth 2004;51: 266-272.

17. Arnold R, Liao S: The palliative care specialist in the intensive care unit: Opportunities for impact. I Palliat Med 2005;8:838-851.

18. Moss AH, Demanelis AR, Murray J, Jack J: Barriers to quality end-of-life care in West Virginia ICU units: Physicians' and nurses' perspectives. W V Med J 2005;101: 200-204.

19. Nelson JE, Angus DC, Weissfeld LA, Puntillo KA, Danis M, Deal D, Levy M, Cook DJ: EOL care for the critically ill: A national ICU survey. Crit Care Med 2006;34:2547-2553.

20. Curtis JR, Engelberg RA: Measuring success of interventions to improve the quality of end-of-life care in the intensive care unit. Crit Care Med 2006;34(11 Suppl):S341-S347.

22. Warren S, Hines S, Moss A: Concerns and self-reported competencies in end-of-life care: A survey of physicians in WV. W V Med J 2000;96:455-457.

23. Nelson J: Identifying and overcoming the barriers to highquality palliative care in the intensive care unit. Crit Care Med 2006;34:S324-S331.

24. Lilly CM, De Meo DL, Sonna LA, Haley KJ, Massaro AF, Wallace RF, Cody S: An intensive communication intervention for the critically ill. Am J Med 2000;109:469-475.

25. Curtis JR, Engelberg RA, Wenrich MD, Nielsen EL, Shannon SE, Treece PD, Tonelli MR, Patrick DL, Robins LS, McGrath BB, Rubenfield GD: Studying communication about end-of- life care during the ICU family conference. Development of a framework. I Crit Care 2002;17:147-160.

26. McDonagh JR, Elliot TB, Engelberg RA, Nielsen EL, Shannon SE, Treece PD, Tonelli MR, Patrick DL, Robins LS, McGrath BB, Rubenfield GD: Family satisfaction with family conferences about end-of-life care in the ICU: Increased proportion of family speech associated with increased satisfaction. Crit Care Med 2004;32:1484-1488.

27. Montagnini ML, Smith HM, Moat ME, O'Leary T, Ojeda KA, Lisowski E: Developing a VA Palliative Care Program. Federal Practitioner 2008;25:18-29.

28. Azoulay E, Timsit JF, Sprung CL, Soares M, Rusinova K, Lafabrie A, Abizanda R, Svantesson M, Rubulotta F, Ricou B, Benoit D, Heyland D, Joynt G, Français A, Azeivedo-Maia P, Owczuk R, Benbenishty J, de Vita M, Valentin A, Ksomos A, Cohen S, Kompan L, Ho K, Abroug F, Kaarlola A, Gerlach H, Kyprianou T, Michalsen A, Chevret S, Schlemmer B; Conflicus Study Investigators and for the Ethics Section of the European Society of Intensive Care Medicine: Prevalence and factors of intensive care unit conflicts. Am J Respir Crit Care Med 2009;180:853-860.

29. Frick S, Uehlinger DE, Zuercher Zenklusen RM: Medical futility: Predicting outcome of intensive care unit patients by nurses and doctors: A prospective comparative study. $\underline{\text { Crit }}$ Care Med 2003;31:456-461.

30. Studdert DM, Mello MM, Burns JP, Puopolo AL, Galper BZ, Truog R, Brennan TA: Conflict in the care of patients with prolonged stay in the ICU: Types, sources, and predictors. Intensive Care Med 2003;29:1489-1497.

31. Beckstrand RL, Kirchhoff KT: Providing end-of-life care to patients: Critical care nurses' perceived obstacles and supportive behaviors. Am J Crit Care 2005;14:395-403.

Address correspondence to:

Marcos Montagnini, M.D., FACP

Division of Geriatric Medicine

University of Michigan

VA Ann Arbor Healthcare System

GRECC (11-G)

2215 Fuller Road

Ann Arbor, MI 48105

E-mail: mmontag@umich.edu 
Appendix 1. Scale of End-of-Life Care in the ICU (EOLC-ICU)

\section{Directions:}

Please read each statement carefully. Check $(X)$ the scale item that best describes your level of agreement with each statement from Strongly Disagree to Strongly

Agree.

\section{I am well prepared to:}

1. Treat pain in the dying patient with pharmacological measures (e.g., opiods, anticonvulsants, antidepressants).

2. Treat pain in the dying patient with nonpharmacological measures (e.g., heat, cold, massage, relaxation techniques).

3. Treat respiratory symptoms in the dying patient (e.g., dyspnea and cough).

4. Treat gastrointestinal symptoms in the dying patient (e.g., nausea, vomiting, constipation, and bowel obstruction).

5. Treat neuro/psychiatric symptoms in the dying patient (e.g., delirium, seizures, anxiety, and restlessness).

6. Discuss advance care planning with patients and families.

7. Discuss code status with patients and families.

8. Withdraw life support in the dying patient.

9. Identify the emotional needs of dying patients and their families.

10. Identify the cultural needs of dying patients and their families.

11. Provide grief and bereavement support to patients and families at end of life.

12. Identify the spiritual needs of dying patients and their families.

I feel:

13. Comfortable discussing advance care planning with patients and families.

14. Comfortable discussing code status with patients and families.

15. Comfortable withdrawing life support in the dying patient.

16. It is important for physicians, nurses, and other ICU team members to collaborate in end-of-life decision making.

17. ICU staff would benefit by commemorating the death of patients in the ICU.

\section{Directions:}

Please read each statement carefully. Check $(X)$ the scale item that best describes your level of agreement with each statement from Strongly Disagree to Strongly

$\begin{array}{lllc}\text { Strongly } & & \text { Strongly } & \text { Not } \\ \text { Disagree } & \text { Disagree Neutral Agree } & \text { Agree } & \text { Applicable }\end{array}$

Agree.

\section{In the ICU:}

18. I initiate advance care planning with patients / families when they are admitted with no documentation of advance care plans.

19. I use the patient's advance directive when developing goals for end-of-life care.

20. Code status is discussed with patients/families in a timely fashion when the patient's clinical status deteriorates.

21. Withdrawal of life support is discussed with patients/families in a timely fashion when the patient's clinical status deteriorates. 
22. Clear and consistent information is provided by team members to patients/families making decisions regarding end-of-life care.

23. Conflicts among team members are addressed before meeting with the patient and/or family.

24. Team members meet with the patient and/or family on a regular basis to review the patient's status and to answer questions.

25. Palliative care experts are consulted in a timely manner for end-of-life issues.

26. We prepare patients and families for changes of clinicians (attending physicians, residents, medical students, nurses, etc.).

27. Continuity of care for the patient/family at end of life is observed when nursing assignments are made.

28. There is sufficient support for staff to handle the personal distress that may arise when caring for patients at end of life.

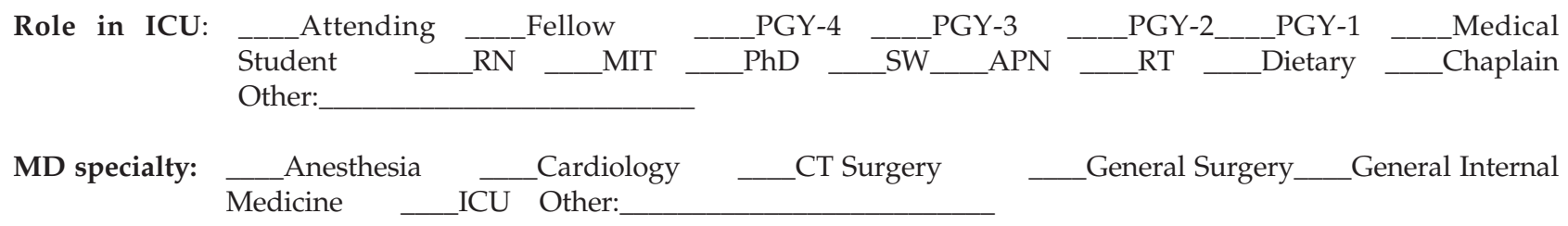

Years in practice:

Previous end-of-life education:

Other: No __ Yes; type: ___ Lectures __ Self-study___Course (\#_

\section{General comments:}


This article has been cited by:

1. Daniel J. Penny, Lara S. Shekerdemian. 2013. The American Heart Association's Recent Scientific Statement on Cardiac Critical Care: Implications for Pediatric Practice. Congenital Heart Disease 8:1, 3-19. [CrossRef] 